\title{
APROPIACIONES DE LA ANTIGÜEDAD. LEGITIMACIÓN DEL PODER Y TRANSMISIÓN DE UN MITO.
}

Appropriating Antiquity. Legitimation of Power and Transmission of a Myth.

\author{
Juan Ramón CARBÓ GARCía \\ Universidad Carlos III de Madrid \\ jrcarbo@hum.uc3m.es
}

Fecha de recepción: 04-02-2010

Fecha de aceptación: 08-02-2010

\begin{abstract}
RESUMEN: Se aborda en estas páginas la presentación del proyecto de investigación desarrollado en torno a la percepción de la Antigüedad y las apropiaciones de ésta realizadas a lo largo de las diferentes edades históricas en varios países y territorios europeos, pero especialmente en España y en Rumanía, para el caso específico planteado de la apropiación de la historia antigua rumana. Mediante el análisis de la historiografía rumana en relación con el nacionalismo en este país, y con el estudio del mito gético -en torno a la confusión e identificación entre los godos y los antiguos pobladores de Rumanía, los getas o daciosy su transmisión en las genealogías míticas europeas desde la propia Antigüedad hasta nuestros días, la investigación pretende constatar con ese ejemplo el gran poder de legitimación y justificación del pretérito, y especialmente del más antiguo, en diferentes momentos y circunstancias nacionales.
\end{abstract}

Palabras clave: historiografía, genealogías, mitos, nacionalismo, godos, getas.

ABSTRACT: On these pages we afford the introduction of the research project developed about the perception of Antiquity and the appropriations of this one exerted along the different historical ages in many European countries and territories; this is specially observed in Spain and Rumania for the posed specific case of appropriations of the Rumanian ancient history. By means of analyzing the Rumanian scholarship related to nationalism in this country and studying the Getic Myth - about the confusion and identification between Goths and the ancient settlers of Rumania, Getae or Dacians - and its transmission on the Euro- 
pean mythical genealogies from Antiquity until our days, this research intends to confirm with that example the great power of legitimation and justification owned by the Past, and specially by the most ancient one, on different times and national circumstances.

Keywords: Scholarship, Genalogies, Myths, Nationalism, Goths, Getae.

Toda investigación histórica debe basarse necesariamente en unos antecedentes y en el estado actual de los conocimientos. En los últimos años, desde Francia, Inglaterra, Alemania, Italia y Estados Unidos se ha venido realizando un esfuerzo importante para lograr establecer cómo se ha percibido la Antigüedad y cómo se ha manipulado en función de los distintos intereses nacionales. Hace ya tiempo, se había determinado con precisión cómo, por ejemplo, la Revolución Francesa y la campaña napoleónica de Egipto, con sus consecuencias culturales, transformaron el modo de pensar la Antigüe$\mathrm{dad}^{1}$. También se ha analizado, por ejemplo, cómo el pensamiento moderno se ha nutrido del legado clásico, en relación con filósofos y pensadores franceses y alemanes fundamentalmente ${ }^{2}$ o cuál ha sido el legado de Roma a la cultura europea. En este sentido, en los años noventa empezó a desarrollarse una historiografía interesada en relacionar la formación de Europa con el legado clásico greco-romano, favoreciéndose este tipo de estudios y congresos por el Centro Cultural "Nicolò Rezzara" di Bergamo y la Università Católica del Sacro Cuore. También fueron organizados varios congresos internacionales sobre el tema "Alle radici della casa comune europea: storia e storiografia dell'Europa

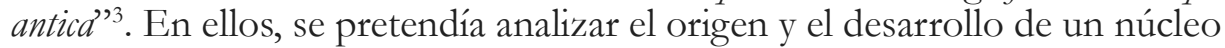
embrionario de historia y de cultura europeas integradas ya antes de que se conformase el mismo concepto Europa o que la Europa real pudiera ser percibida como una entidad definida. Además, también se han estudiado algunas apropiaciones de la Antigüedad durante la época tardía y durante la Edad Media, en relación más directa con nuestro estudio específico, haciendo alusión a las genealogías míticas de los godos, como veremos enseguida ${ }^{4}$. En España se ha comenzado a despertar un mayor interés sobre este tipo de temas en los últimos años, si bien siguen siendo insustituibles los estudios de Luis Gil, Panorama social del humanismo español (1500-1800) y Estudios del bumanismo y tradición clásica ${ }^{5}$. Ahora bien, aún quedan cuestiones importantes por investigar, como el estudio de las genealogías míticas en el origen de los pueblos, las dinastías reinantes y las grandes familias de la nobleza, así como el estudio de las tradiciones mitológicas que se recuperan en España frente a la recuperación simultánea que se está realizando en los restantes países europeos ${ }^{6}$.

Varios grupos de investigación internacionales trabajan sobre estos aspectos, con algunas variantes. El proyecto internacional "Histoire et Pouvoir", 
que tiene su sede en el Centre de recherche du chatteau de Versailles (CRCV), toma como punto de partida la conexión existente entre la construcción de los Estados modernos y la práctica histórica, y tiene como objetivo el estudio de los modelos explícitos y subyacentes del discurso político en Europa en una perspectiva de transversalidad disciplinar. En relación con el Centre de Recherche ESR (Université de Versailles Saint-Quentin-en-Yvelines) tiene una dilatada experiencia en el estudio de la Historia y sus usos durante la Edad Moderna ${ }^{7}$. Por otro lado, el grupo de investigación histórica hispano-alemán POTESTAS que desarrollan las Universidades de Potsdam y Jaume I de Castellón, está centrado en el estudio de la historiografía de la construcción del concepto de Europa y sus formas de representación ${ }^{8}$. El grupo europeo BAT (Bibliotheca Academica Translationum) centra su atención en el estudio de las traducciones de obras sobre la Antigüedad con el fin de detectar cómo se produce la transferencia europea del conocimiento sobre el mundo clásico entre los siglos XVIII y XIX. El proyecto que desarrolla este grupo de investigación permite la visualización del uso de las traducciones como elemento de conformación de los nacionalismos tanto desde las traducciones de las fuentes clásicas a las lenguas modernas, como del empleo de los análisis modernos en la conformación de las ideologías nacionalistas?. Y es que el énfasis del nacionalismo decimonónico y del siglo XX se percibe a través de la instrumentalización de la Antigüedad en todas las manifestaciones culturales. Sirva ahora de ejemplo, el empleo de las figuras de caudillos indígenas como Viriato (España), Vercingetorix (Francia), Arminio (Alemania), Boadicea (Inglaterra) o Burebista y Decébalo (Rumanía) ${ }^{10}$.

Pero el estudio en curso, cuyos antecedentes, fundamentos, finalidad, objetivos y primeros resultados queremos presentar en estas páginas, tiene como punto de partida dos proyectos de investigación, eminentemente. En primer lugar, el proyecto "Relaciones de poder en el Imperio Romano: Resistencia, sumisión e interiorización de la dependencia (ss. I-VI d.C.)", desarrollado por el grupo de investigación reconocido de la Universidad de Salamanca, EPIRUS (Estudios sobre el Poder en el Imperio Romano, de la Universidad de Salamanca), encabezado por la profesora de esta universidad María José Hidalgo de la Vega. Este proyecto, continuado ahora en otro en el que se encuadra este trabajo, contaba entre sus objetivos el estudio del proceso evolutivo del discurso en la historiografía altoimperial y bajoimperial con respecto a los pueblos bárbaros, desde un discurso y una práctica política de exterminio hasta una actitud activa de integración y clemencia que acaba explicando la formación de los distintos reinos bárbaros que coexistieron y finalmente suplantaron al Imperio Romano en su parte occidental y que buscaron una justificación y legitimación de su existencia en el uso de la historia de otros pueblos. 
Otro antecendente evidente es el proyecto actualmente vigente del Instituto de Historiografía "Julio Caro Baroja", de la Universidad Carlos III de Madrid, "La Antigüedad en la creación de mitologías políticas y de las conciencias nacionales (siglos XV T-XIX)", del que el profesor Jaime Alvar Ezquerra es el Investigador Principal. Precisamente, el equipo por él encabezado ha tenido como una de sus principales líneas de investigación el estudio del proceso de creación de la Historia y del Pasado grecorromanos (como disciplina y representación o prefiguración cultural, respectivamente), su difusión y su repercusión en las diferentes esferas de nuestra cultura, con especial atención a la política. En consecuencia, han sido varios los proyectos, actividades de investigación y publicaciones dedicadas a esta temática que se han desarrollado desde el Instituto de Historiografía ${ }^{11}$. Pero sin duda alguna, el objetivo que mejor enlaza con el proyecto que aquí se presenta es el análisis de los procesos de construcción de una Antigüedad a la medida de los intereses ideológicos, a través de la elaboración de los tópicos de la historia nacional, de las estampas de la Antigüedad empleadas en la construcción de modelos ideológicos y de la comparación entre procesos nacionalistas de distinta naturaleza, como son los de España y Rumanía en el siglo XX, con sus apropiaciones del pasado, conectado en la Antigüedad a través del mito.

Nuestro proyecto de trabajo de investigación parte de la hipótesis de que a partir del Renacimiento se desarrolla con intensidad una dinámica centrípeta estatal, que afecta a las diferentes genealogías presentes en cada uno de los espacios político-sociales, provocando fricciones entre éstas, en pos de un único y homogéneo linaje mítico nacional. Del mismo modo, en la Península Ibérica, durante el siglo XV y en el reinado de los Reyes Católicos, este proceso de homogenización de genealogías nacionales busca por un lado la legitimación del poder, por otro, la justificación de la preeminencia social, y también el prestigio deseado por un grupo determinado. La elaboración de genealogías imaginarias desde la Tardoantigüedad se basa en la apropiación de factores históricos aún más antiguos y con el paso de los siglos da lugar a una verdadera producción historiográfica específica dedicada a la reelaboración de los linajes genealógicos que hunden sus raíces en la Antigüedad. Asimismo, la genealogía preeminente (o triunfante) será transmitida parcialmente por medio de la simbología presente en la heráldica, que será utilizada como forma de propaganda de esa genealogía y que ayudará a su popularización, y siendo incluso recuperada en el siglo XX bajo el prisma de la conciencia nacional impuesta por el régimen franquista, de modo que dicha genealogía mítica llega hasta el presente desde sus orígenes en la Antigüedad.

Con nuestro estudio pretendemos analizar una parte peculiar del proceso de construcción y sustentación de genealogías remotas desde la misma Antigüedad, la Tardoantigüedad hispana, los reinos hispánicos medievales y 
el estado moderno de los Reyes Católicos, hasta el nacimiento del partido fascista español, el régimen franquista y la monarquía constitucional actual, con sus respectivas apropiaciones del pasado en busca de la legitimación de su poder, a través del estudio de uno de esos mitos que ha perdurado a lo largo de las edades históricas, pero que hunde sus raíces en el espacio mítico de la Antigüedad.

De este modo, el proyecto estudia el uso del mundo antiguo en la creación de las genealogías míticas legitimadoras y en la simbología y la heráldica de algunos de los pueblos-nación europeos, aunque especialmente en lo que se refiere al espacio de la Península Ibérica, y en sus diferentes estratos sociopolíticos, los cuales revelan una misma estructura mítica del relato histórico: para la Monarquía, la constitución y legitimación de dinastías reales basadas en genealogías míticas; para la Dictadura, el uso de una simbología apropiada de la Monarquía de época moderna y basada a su vez en genealogías míticas, o bien la apropiación de símbolos de la Antigüedad nacional; para la nobleza, la construcción de linajes nobiliarios con genealogías míticas; para la burguesía, la bonhomía clásica en la construcción de nuevos modelos de excelencia política o patrones de comportamiento político basados también en la mitología o genealogías urbanas; por otro lado, el pueblo aparece como sujeto pasivo de la aceptación de una identidad nacional ancestral creada por otros, cualquiera de los anteriores.

Hesíodo, en su Teogonía, uno de los textos genealógicos más antiguos de la tradición griega, ya mostraba lo que era el conocimiento genealógico desde sus orígenes: un deseo de gloria y de curiosidad por el origen de las cosas, lo cual conduce inevitablemente a la causa de los hechos genealógicos, coitio y filiatio:

¡S alud, hijas de Zeus! Dadme un canto placentero. Celebrad el linaje de los sempiternos Inmortales, los que nacieron de Gea y del estrellado Urano, de la oscura Noche y a los que crió el salobre Ponto. Decid cómo nacieron en un principio los dioses, la tierra...12.

Las posibles coitiones y la seguridad de las filiationes condicionan el funcionamiento de la sociedad y del Estado. El orden en la genealogía de los dioses había de ser fundamental para el correspondiente orden en el mundo. Por consiguiente, esos tres factores mencionados - orígenes, orden y gloriamuestran por qué resulta necesario el estudio de la genealogía, que se remonta hasta las genealogías ficticias, en la Europa moderna y contemporánea en general, y en España en particular.

Desde la misma Antigüedad se produjo la confusión y también la identificación consciente entre dos etnónimos y posteriormente entre los pueblos a los que daban nombre: los gothi-los godos-y los getae -los getas. Estos últimos eran un pueblo de la Antigüedad localizado en el territorio compren- 
dido en la actual Rumanía y frecuentemente considerado como una denominación distinta de los dacios, con una leve variación geográfica y cultural, pero en cualquier caso perteneciendo a la rama de los tracios septentrionales, como los dacios $^{13}$. Con esa confusión e identificación consciente, se produce una apropiación de su historia y de su identidad, y la elaboración de una genealogía fantástica, tal y como aparece reflejada en las obras de diferentes autores antiguos y especialmente de la Antigüedad Tardía, entre los que podemos mencionar a Orosio ${ }^{14}$, Casiodoro, Jordanes ${ }^{15}$ o Isidoro de Sevilla ${ }^{16}$, que en distintas épocas y ámbitos geográficos buscaron legitimar a los godos situando sus orígenes en un momento más antiguo, pues cuanto más lejos en el tiempo pudiesen encontrarse esos orígenes, mayor prestigio se obtendría. Cuando los visigodos se asentaron en Hispania y la idea de una nación gótica fue desarrollada por Isidoro de Sevilla, una parte de la historia de los getas y dacios fue incorporada mediante las genealogías míticas a la que luego daría lugar a la historia nacional española.

En la Edad Media peninsular, las obras de diferentes autores, como el obispo Rodrigo Jiménez de Rada ${ }^{17}$, Lucas de Tuy ${ }^{18}$, o el mismo rey Alfonso $\mathrm{X}$ el Sabio ${ }^{19}$, incorporaron los mitos, leyendas, la historia y las genealogías de otros pueblos, como los getas y dacios, como una forma de exaltación del pasado godo, de su justificación y de su legitimación socio-política, ya que eran el precedente peninsular y modelo histórico para la realeza hispánica medieval.

La continuidad de esta confusión e identificación en otras partes de Europa también se constata en varias fuentes históricas y geográficas de la Edad Media, como las obras de Adán de Bremen o de Guillermo de Jumièges, así como en el período moderno temprano. En algunos mapas medievales, Dinamarca aparece denominada como Dacia -el territorio de la Antigüedad situado grosso modo sobre lo que hoy sería Rumanía- o bien Gothia, y en ese período, Daci llega a convertirse en un sinónimo de Dani, para referirse a los daneses escandinavos, al igual que Getae lo fue de Gothiz. En el siglo XI, Guillermo de Jumièges escribió la crónica de los Duques de Normandía -Gesta Normannorum Ducum - y al elaborar su genealogía mítica nobiliaria investigó sus fabulosos orígenes hasta situarlos en Dinamarca, pero refiriéndose a ella como Dacia, según él habitada por los godos, que a su vez habían contado entre sus más renombrados monarcas a los que en realidad fueron mucho antes los viejos dioses y reyes getas y dacios, como Zalmoxis, Burebista o Decébalo ${ }^{21}$. En una época tan tardía, en este sentido, como finales del siglo XVI, getae será todavía el nombre poético utilizado para referirse a los bárbaros enemigos de la Cristiandad, como los turcos, y es que así aparecen denominados éstos en las fuentes epigráficas en Malta en la época del gran asedio de 1565, sobre la tumba del gran maestre de la orden de los caballeros hospitalarios de San Juan, Jean Parisot de La Vallette, en una prueba 
más de la continuidad temporal de la confusión e identificación de la noción de getae con la de gothi2 .

La producción de genealogías sirve de modelo en la Modernidad. De hecho, las genealogías míticas se convierten en algo indispensable para las dinastías reinantes y más aún para las grandes familias de la nobleza. La disciplina genealógica suministra datos interesantes para comprender los mecanismos de identificación social y nacional. Es imprescindible conocer la manera a través de la cual sociedades, familias y particulares imaginaban sus orígenes, los relataban y, finalmente, los confrontaban unos con otros. La genealogía, pues, se constituye como una herramienta de control social. En época renacentista, cuando el descubrimiento y la edición de los autores antiguos abrían nuevos campos para la reflexión, un gran interés por el pasado, antiguo y nacional, suscitó numerosas investigaciones que generaron en toda Europa múltiples publicaciones. La imprenta tuvo un papel fundamental, pues había proporcionado una gran cantidad de fuentes que enriquecían la práctica histórica. Resulta, así pues, de gran importancia estudiar los lazos que existen entre el desarrollo del conocimiento histórico y la construcción de las grandes monarquías y los Estados modernos, pues ambos son fenómenos concomitantes. En un contexto de rivalidades entre Estados, estudiar la manera a través de la cual la Historia ha servido de legitimación política y de crisol en la elaboración de las conciencias nacionales contribuye al conocimiento de las distintas posiciones del discurso histórico, así como a comprender su naturaleza y su alcance.

En este sentido, y volviendo a la Península, durante el siglo XV se produce el surgimiento de los ideales neo-góticos en Castilla y las tradiciones góticas prevalecen en esa época, tal y como se observa en la obra del obispo Alonso de Cartagena, en la que sobrevive la confusión gética gracias a la llegada a la Península de la obra de Jordanes ${ }^{23}$. En lugar de remontarse al prestigio del mundo clásico, en Castilla se busca como modelo para la producción de sus dinastías reinantes las genealogías godas ${ }^{24}$, donde preexistía la genealogía ficticia del mito gético. Asimismo, éste se refleja en la imagen de esa genealogía que pretende transmitir la monarquía de los Reyes Católicos, con la elección de las flechas, junto al yugo, como símbolos para los dos monarcas, por el humanista Elio Antonio de Nebrija, así como su inclusión junto al escudo real, que aparecerá en múltiples edificios a lo largo y ancho de sus reinos $^{25}$. En la literatura de viajes de la Edad Moderna, en el siglo XVII, encontramos la narración que hace Cosme -O Cosimo- III de Médicis de sus viajes por España. Cosimo, Gran Duque de la Toscana y Florencia, emparentado desde varias generaciones con la más alta nobleza hispánica, identifica los emblemas -y más claramente las flechas- como símbolos góticos, tomados por los Reyes Católicos con la clara intención de entroncar con la tradición gótica y de ese modo mostrar en la heráldica la genealogía de los 
monarcas, es decir, que descendían de los reyes visigodos, que habían reinado sobre toda la Península Ibérica ${ }^{26}$. Pero como también se puede observar a partir del estudio de las fuentes clásicas en las que se produjo en un primer momento la confusión y la identificación entre getas y godos, las flechas elegidas para Isabel tienen realmente su origen en un pasaje que hace referencia a las flechas de los getas, y no a los godos ${ }^{27}$. El mito persiste desde ese momento por medio de un símbolo que es expresión de la genealogía de los reyes, de modo que la heráldica resulta igualmente interesante a este respecto.

Durante los siglos siguientes y hasta el siglo XIX, diversos historiadores y escritores políticos de distintas épocas han destacado e incluso exaltado el origen godo de la monarquía y sociedad españolas y a este respecto, resulta relevante que el título oficial de Reyes Godos fuese detentado por los reyes españoles nada menos que hasta la constitución de $1812^{28}$. El término "godo" tuvo el significado de "legitimista" a principios del siglo XIX y asimismo tiene desde entonces una connotación negativa para referirse al conjunto de los españoles, especialmente los peninsulares. Así pues, el pueblo español se revela ya no sólo como sujeto pasivo de la aceptación de una identidad nacional ancestral creada por otros, en este caso la monarquía y la nobleza, sino que también es objeto de la adjudicación peyorativa de esa misma identidad nacional ancestral.

Ya en el siglo XX, la dictadura franquista y su historiografía afín tomaron como modelo ideal para España el reinado de los Reyes Católicos, y la Falange, el partido fascista español, adoptó incluso el emblema del yugo y las flechas superpuestas, que sería incorporado al escudo nacional español, igualmente un remedo de las armas de los citados monarcas. El mito se reactiva y con él las genealogías de reyes godos peninsulares, protagonistas de uno de los tópicos más extendidos sobre lo que era la enseñanza de la historia durante el régimen franquista. Resulta de interés la perspectiva franquista y falangista de la Antigüedad, y su apropiación del pasado mediante el uso de unos símbolos presentes en la heráldica y en la simbología españolas durante cinco siglos, pero que igualmente parecen haber tenido su origen en la Antigüedad y en las construcciones imaginarias del pasado ${ }^{29}$. Y si el pasado se apropia de un pasado más antiguo, mediante los mecanismos y por los intereses ya expuestos, la última expresión del mito gético, de su pervivencia en la heráldica, que es un tipo de expresión simbólica de las genealogías, la encontramos en el escudo heráldico del rey Juan Carlos I. En él, todavía siguen apareciendo el yugo y las flechas, herederos directos de los símbolos del régimen franquista, que a su vez los había tomado de los Reyes Católicos, los cuales los habían tomado de los godos, que por su parte se habían apropiado de la historia de getas y dacios, de la que se toma igualmente la referencia de las flechas. 
Desde esta perspectiva, el proyecto que venimos desarrollando pretende abordar el estudio de todos los aspectos mencionados siguiendo el hilo conductor de la transmisión del mito gético, nacido de las confecciones de las genealogías míticas de los pueblos, revivido con las dinastías reinventadas en el Renacimiento y transmitido hasta la actualidad gracias a la simbología presente en la heráldica hispana, como expresión propagandística de la ascendencia genealógica sobre la que se basan y con la que buscan legitimarse y darse el prestigio antigo, por un lado el poder dictatorial y la ideología falangista, y por otro, la monarquía constitucional de finales del siglo XX.

Las novedades de la investigación son tres: en primer lugar, el análisis de las apropiaciones y el uso que de su propia historia antigua -la historia de getas y dacios-han hecho el poder y la historiografía rumana en su afán por establecer los orígenes del pueblo rumano y de esa forma legitimar su propia existencia y la del propio estado rumano, y la comparación de esas apropiaciones con las realizadas por distintos pueblos/naciones europeos de esa misma historia de los pueblos antiguos getas y dacios, especialmente en el caso de España.

En segundo lugar, la aceptación como punto de partida del mismo objeto de apropiación. Esto es, se parte del estudio de la creación de las mitologías políticas en torno a los godos en la misma Antigüedad, plasmadas en las obras de autores antiguos y especialmente tardoantiguos, como Orosio, Casiodoro, Jordanes o Isidoro de Sevilla, que en su momento contribuyeron a generar genealogías míticas legitimadoras del poder o imágenes cohesionadoras de un ethnos gothicum que llegará a ser nación gótica. De este modo, una vez detectado el mecanismo apropiador, se intentará mostrar cómo éste, adquirido y redescubierto por aquellos intelectuales orgánicos al servicio del poder desde el Renacimiento, se revitaliza con la única finalidad de legitimación nacional, independientemente de su historicidad.

Y en tercer lugar, el estudio de la constitución del estado moderno en España desde el Renacimiento hasta el siglo XX a través de sus discursos y representaciones simbólicas de uno de esos mitos, el mito gético, que se presenta como árbol en el que entroncan las apropiaciones históricas en las diferentes edades y que hunde sus raíces en la Antigüedad, siendo así el núcleo central de nuestro trabajo.

Para poder lograr ese estudio novedoso, nos hemos propuesto desde un principio varios objetivos concretos: el estudio de la confusión e identificación consciente entre getas y godos en la Antigüedad en los autores clásicos; el estudio de la construcción de las mitologías ficticias del pueblo godo en la Antigüedad, con la etnogénesis goda en Amiano Marcelino y el uso de la historia de getas y dacios por Orosio, Casiodoro o Jordanes; el estudio del afianzamiento de las genealogías míticas visigodas en la historia de España 
durante la Antigüedad Tardía y la Edad Media, en autores como Isidoro de Sevilla, Rodrigo Jiménez de Rada, Lucas de Tuy o Alfonso X el Sabio; el estudio de la construcción mítica de las dinastías reinantes en la Península Ibérica a comienzos de la Modernidad, con los Reyes Católicos, en el contexto del renacer de los ideales neo-góticos en Castilla, y el estudio concreto del modelo de la obra del obispo Alonso de Cartagena; el análisis de las representaciones de la genealogía mítica homogeneizada para los españoles en la simbología presente en la heráldica, desde los Reyes Católicos hasta el siglo $\mathrm{XX}$, con la Falange; y el estudio de los orígenes míticos del pueblo rumano, con especial hincapié en la comparación entre los casos de España y Rumanía, y las apropiaciones y el uso de la Antigüedad para la conformación de las identidades nacionales respectivas en los siglos XIX y XX.

$\mathrm{El}$ análisis de los aspectos mencionados viene siendo realizado desde una perspectiva comparativa y transnacional, y con una práctica metodológica e historiográfica que debe ayudar a buscar las relaciones entre la presencia de ciertas mentalidades, ideas, prácticas culturales y objetos simbólicos como medios de establecimiento del poder, su legitimación y la formación de identidades, del ethnos que deviene nación, en cada una de las diferentes edades históricas, desde la Antigüedad hasta el siglo XX, y en diferentes países y territorios europeos, aunque con especial hincapié en los casos comparados de España y de Rumanía. La presencia del que se ha denominado "mito gético", esto es, la confusión e identificación entre getas y godos, y la confección de genealogías míticas para los godos apropiándose de la historia de los getas y los dacios, es un hilo conductor a través de las edades históricas y los distintos territorios. En ese sentido, intentamos sobrepasar los límites temporales y geográficos con respecto a nuestro pensamiento histórico y cultural, e intentamos de igual modo repensar la historia de Europa a través de su naturaleza dinámica, de sus interacciones sociales y culturales.

Un proyecto de investigación como éste, con un marco temporal tan extenso y unas perspectivas tan amplias, debe desarrollarse a largo plazo, y más aún cuando el investigador no se dedica a él de forma exclusiva. En el estado actual de su desarrollo, sin embargo, podemos avanzar que ya se han obtenido resultados en forma de aproximaciones preliminares, estudios parciales y establecimiento de la línea temática de conexión que constituye el mito gético. En particular, se ha prestado una mayor atención a la formación y transmisión del mito en la Antigüedad y el Medievo en la Península Ibérica, se han analizado también algunos casos de transmisión del mito en otras zonas de Europa y se ha elaborado y argumentado toda la teoría sobre el primigenio origen gético de las flechas usadas en el emblema personal de la reina Isabel I de Castilla, así como los procesos de elección tanto por Nebrija para los Reyes Católicos como por Juan Aparicio López y Rafael Sánchez Mazas para la Falange, en forma de varios artículos publicados en España y en Rumanía ${ }^{30}$. 
Durante los dos últimos años, la investigación se ha centrado en otro de los objetivos planteados inicialmente, el del estudio de los orígenes míticos del pueblo rumano y las apropiaciones y el uso de la Antigüedad para la conformación de la identidad nacional de Rumanía en los siglos XIX y XX, especialmente, en comparación con el caso español. Aunque es una investigación abierta y seguimos trabajando en ello, ya se han obtenido algunos resultados de esa labor en forma de conferencias, ponencias y artícu$\operatorname{los}^{31}$. A estos últimos resultados quiero referirme brevemente para finalizar esta exposición de la investigación que estamos desarrollando y plantear al mismo tiempo cuáles serán los objetos de estudio inmediatos a partir de este momento.

Las explicaciones de los orígenes de los rumanos podrían agruparse en tres tendencias, cada una de las cuales ha conseguido influir en mayor o menor grado en los debates modernos en torno a la historia antigua del país. La primera tendencia, la de los "latinistas", identifica a los rumanos como descendientes de los pobladores y soldados romanos de la época provincial, por lo que en su pico de mayor influencia, tendieron a enfatizar los lazos de Rumanía con Occidente. Una segunda tendencia, claramente contrapuesta, es la de los "dacianistas", que identifican a los rumanos como descendientes de los dacios. Por supuesto, aceptan que aquéllos adoptaron el latín de sus conquistadores, pero proclaman la independencia del pueblo rumano respecto a poderes exteriores. La tercera tendencia, la más aceptada hoy en día, podría denominarse "daco-romanista", haciendo alusión a una mezcla entre colonos romanos e indígenas dacios para explicar la ascendencia de los rumanos. Las tres tendencias sostienen la existencia de algún tipo de continuidad poblacional sobre el territorio desde la época romana hasta la actualidad, un postulado que ha presentado ciertas implicaciones problemáticas en cuanto a las relaciones con algunos países limítrofes -especialmente, Hungría- y las reivindicaciones territoriales, empezando por el propio tamaño y delimitación geográfica del Estado rumano, que sólo alcanzó su configuración definitiva actual al término de la Segunda Guerra Mundial.

Desde el siglo XV, en el marco de las continuas campañas militares contra la expansión otomana, se puede observar ya una utilización ideológica de los orígenes latinos para explicar la ascendencia de los rumanos en la zona, y se comprueba en la documentación de la correspondencia diplomática con el Papado de Roma y con otros estados occidentales del momento que ya entonces se enfatizaban los orígenes latinos de los rumanos y también el carácter de la región como baluarte defensivo de la Cristiandad frente a la amenaza turca. Desde entonces se había ido configurando la identidad diferenciada de los rumanos y de su lengua respecto a la de los pueblos vecinos con los que cohabitaban. Y desde el siglo XVII, la incipiente historiografía rumana representada por los cronistas moldavos Mihail Moxa, Grigore 
Ureche, Miron Costin, Ion Neculce y el príncipe Dimitrie Cantemir ${ }^{32}$ soportaba la idea del origen romano de los rumanos, así como el origen latino de la lengua rumana, como seña de identidad propia, distintiva y en suma, nacional, al menos desde el punto de vista étnico y lingüístico, frente a los imperios circundantes, como el Imperio Otomano, el Reino de Hungría, el Imperio Austriaco y el Imperio Ruso, y también frente a las naciones con las que los rumanos cohabitaron en la región de Transilvania ${ }^{33}$.

De igual modo, a finales del siglo XVII, en 1698, tuvo lugar un importante acontecimiento que aceleró igualmente la conformación de la identidad nacional rumana. Ese año se produjo la unión de parte de los rumanos ortodoxos de Transilvania con la Iglesia católica: la Iglesia rumana unida con Roma, conocida popularmente como Iglesia greco-católica ${ }^{34}$. Entraron en plena comunión con la sede de Roma, a la vez que conservaban su rito litúrgico bizantino: dicho de otro modo, mantenían el rito ortodoxo, pero aceptaban la obediencia al Papa de los católicos. A diferencia de la Iglesia ortodoxa rumana, que hasta 1863 oficialmente siguió usando el eslavo eclesiástico en la liturgia, la Iglesia greco-católica rumana unida con Roma usaba la lengua vernácula rumana, una lengua romance, esto es, de origen latino. Entonces se produjo un contacto continuado con Italia y su cultura, lo que llevó a una nueva concienciación del origen romano del pueblo y de la lengua rumanos ${ }^{35}$.

Algo más tarde, en la época del Imperio Austriaco de los Habsburgos, y más concretamente en el siglo XVIII, en Transilvania se produjo una corriente intelectual de ambientación ilustrada, católica, latinista e italianizante, conocida con el nombre de Escuela de Transilvania (Şcoala ardeleană), que luchó además por la imposición del alfabeto latino para la escritura de la lengua rumana, en lugar del cirílico ${ }^{3}$. Esta Escuela de Transilvania, formada sobre todo por miembros de la recientemente constituida Iglesia greco-católica, hizo hincapié en la descendencia literal del pueblo rumano a partir de los colonos y soldados romanos presentes en la antigua Dacia, y desarrolló la teoría de la exterminación de los dacios, el pueblo autóctono prerromano, conformando una tesis o tendencia que recibiría el nombre de "latinista". Su carácter, que podría adscribirse a la Ilustración alemana (Aufklärung), se diferenciaba de la Ilustración francesa porque la Escuela de Transilvania no desarrolló una corriente anticlerical, al estar estrechamente relacionada con la neonata Iglesia greco-católica ${ }^{37}$.

Las ideas sostenidas por los cronistas moldavos y después por la Escuela de Transilvania jugaron un papel fundamental en la creación de la identidad nacional rumana en épocas anteriores y desde luego, sobre todo en el siglo XVIII y el siglo XIX, junto con un proyecto político común que acabaría llevando a la unidad política. Y de la mano de la Escuela de Transilvania y de esta tendencia historiográfica latinista que reafirmaba el origen romano 
de los rumanos transcurrieron los siglos XVIII y XIX, y dio comienzo el siglo XX con la ya mencionada unificación de todos los territorios donde los rumanos eran el elemento poblacional claramente mayoritario: Moldavia, Valaquia y Transilvania ${ }^{38}$.

La conclusión obtenida del estudio de esta primera tendencia en comparación con otros casos europeos es que para los siglos mencionados, si en los casos de otras naciones europeas se buscaba de algún modo sacudirse la influencia y ascendiente de la tradición clásica, presente y dominante en Europa durante siglos, y recuperar el origen autóctono de los pueblos que forman esas naciones modernas, en el caso de los rumanos se buscó exactamente lo contrario, esto es, reafirmar el origen romano del pueblo y de la lengua rumanos, como seña de identidad propia, distintiva y en suma, nacional, al menos desde el punto de vista étnico y lingüístico, frente a las naciones circundantes y su expansión imperialista $\square$ el Imperio Otomano, el Reino de Hungría, el Imperio Austriaco y el Imperio Ruso $\square$ y también frente a las naciones con las que los rumanos cohabitaron en Transilvania ${ }^{3}$.

Pero si las generaciones previas habían logrado cumplir el gran deseo común de la creación de un Estado moderno y europeo, independiente y que reuniera todos los territorios rumanos en una unidad nacional con una lengua propia, la nueva generación de jóvenes buscaría ahora sus propias vías y aspiraciones, con la redefinición de la cultura nacional en pos de la especificidad, preconizando la búsqueda y la experiencia de lo «auténtico». Esta joven generación, como la de 1927, encabezada por Mircea Eliade, va a querer reencontrar su verdadero carácter, porque teme su pérdida: los rumanos son latinos, pero al mismo tiempo son ortodoxos; y son europeos, pero también participan de una tradición oriental.

A partir de la producción del poeta y dramaturgo rumano Lucian Blaga (1895-1961) y especialmente con su obra teatral Zamolxe, hemos realizado igualmente una exploración del debate sobre la «especificidad nacional» en la Rumanía de entreguerras y también en la época comunista, con la reevaluación historiográfica del tema de la herencia dácica y la búsqueda de la identidad autóctona en un contexto cultural general que estaba dominado por el nacionalismo ${ }^{40}$. Lucian Blaga desafió las perspectivas dominantes en aquellos momentos, en las que prevalecían las tendencias latinistas en la formación del pueblo rumano, y poco después, la historiografía rumana, con el historiador Vasile Pârvan a la cabeza, siguió su ejemplo, dando comienzo a las tendencias dacianistas, que situaban a los antiguos dacios como origen de la cultura y del pueblo rumanos ${ }^{41}$.

La tendencia "dacianista" surgió como respuesta al trabajo desarrollado por la Escuela de Transilvania a favor de la postura "latinista". Durante las protestas en contra de la Iglesia Greco-Católica, vista como una creación po- 
lítica de Austria y del Papado, se afirmaba que los rumanos eran descendientes de los antiguos dacios, de forma que remontaban su origen en el pasado más atrás de los romanos y al mismo tiempo reivindicaban un territorio más extenso para Rumanía, ya que el reino dacio prerromano en el siglo I a.C., en época de su rey Burebista, tenía unos límites mucho mayores que los de la provincia resultante de la conquista por Roma. La utilización política de esta tendencia es incluso más evidente que la anterior, ya que servía para reafirmar la independencia de Rumanía y criticar su unión con el Occidente europeo: las provincias de Dacia eran parte de un imperio extranjero, el romano -como sucedía con Transilvania respecto al Imperio Austriaco / Austro-Húngaro-, mientras que el reino dacio prerromano era un poder independiente. Esa misma posición se usó para reforzar la independencia rumana frente a poderes externos como los austro-húngaros, los rusos o - en el aspecto religioso, legitimador del poder- los católicos, identificados siempre con Occidente. Pero mientras proclamaban su rechazo a la imitación de un Occidente corruptor, los dacianistas no hacían otra cosa que imitar al mismo Occidente en la búsqueda de unos orígenes profundos, antiguos, auténticos, gloriosos... Al igual que hicieron, por otra parte, los otros precursores históricos en la Europa de la extrema derecha y la Nenordnung: para la Italia fascista, el Imperio Romano; para la Alemania nazi, el pasado ario y germánico; y para la España franquista, la Hispania visigoda y el reino de los Reyes Católicos ${ }^{42}$.

Sin embargo, ninguna de las distintas facciones dacianistas anteriores llegó a usar la herramienta ideológica legitimadora en torno a la búsqueda de los orígenes en los niveles en que lo hizo la historiografía marxista de corte nacionalista-estatalizante, próxima al gobierno comunista rumano de Nicolae Ceauşescu durante las décadas de los 70 y 80 del siglo XX. El presidente de Rumanía desarrolló, para aplicarla a su país, la noción de un "Estado dacio independiente y centralizado" y utilizó la tendencia dacianista para legitimarla, mientras que su hermano, Ilie, militar e historiador, y ministro del Ejército, fue más allá e incorporó esa idea en los libros de historia y en estudios doctrinales sobre la defensa en Rumanía, pensando que el modelo dacio serviría para unir el ejército y el pueblo contra cualquier amenaza exterior ${ }^{43}$. La utilización del modelo dacio se convirtió de ese modo para Ceauşescu en una verdadera obsesión y es un perfecto ejemplo del uso y abuso que de la historia han hecho y lamentablemente siguen haciendo distintos regímenes y partidos políticos, pero especialmente los más extremistas y totalitarios, que siempre tienen una mayor necesidad de buscar algún tipo de legitimación, ya que generalmente no la encuentran en las urnas de la democracia.

No obstante, años antes incluso de la muerte de Ceauşescu y del final de su régimen en Rumanía, en 1986 surgieron de la mano del historiador Nicolae Copoiu unas nuevas propuestas que darían lugar a una tercera tendencia, la más aceptada hoy en día, que podría denominarse «daco-romanista», 
haciendo alusión a una mezcla entre colonos romanos e indígenas dacios para explicar la ascendencia de los rumanos ${ }^{44}$. En 1986, Nicolae Copoiu, un investigador del Instituto del Partido para Estudios Históricos y Socio-Políticos, en Bucarest, afirmó que era un error aceptar la validez del concepto de romanización para el caso de Dacia ya que, según él, ello implicaba la desaparición de los dacios de la historia. Sin embargo, la idea de cualquier relación entre dacios y romanos resultaba bastante desagradable para los historiadores y políticos próximos a Ilie Ceauşescu. De forma inmediata se intentó truncar la propuesta de Copoiu, pero desde 1989, con la revolución y la llegada de la democracia a Rumanía, se avivó el interés por la propuesta de la coexistencia e interrelación de dacios y romanos en época provincial y después del abandono romano de Dacia, y más recientemente, lo que ello podría suponer de cara a la integración europea, que finalmente se alcanzó con la entrada de Rumanía en la Unión en enero de 2007.

En todo este estudio historiográfico, el único ejemplo detectado de elaboración de una historia mítica sobre los orígenes de los rumanos fue la obra de Nicolae Densuşianu, La Dacie préhistoriquet, publicada a comienzos del siglo XX, donde el autor exponía su tesis de que el espacio antiguo de Rumanía habría estado habitado por los pelasgos y los hiperbóreos, constituyendo un poderoso imperio en torno al Mediterráneo del que habrían nacido todas las otras civilizaciones. De ese modo, el latín y el dacio habrían sido dialectos de una misma lengua y los latinos provendrían de la Dacia, en una curiosa inversión de la filiación, que será luego oficializada en los escritos de los seguidores de Densuşianu en torno a los años 40, en el marco del "dacianismo" y de la predilección política por el autoctonismo, llegando a sostener nada menos que el origen dacio de las naciones y las lenguas europeas. Sus tesis serán resucitadas a mediados de los años 70 por la historiografía próxima al Partido Comunista Rumano y se convertirán en un dogma para los así llamados "dacómanos" o "tracómanos".

Pero en estos momentos todavía no hemos realizado un estudio más profundo sobre esta última variante historiográfica del "dacianismo" en relación con el nacionalismo rumano del siglo XX y sus apropiaciones de la Antigüedad, de modo que será objeto de atención inminente de un próximo estudio en el marco de nuestra investigación.

Con todo ello, estamos verificando las distintas apropiaciones de la Antigüedad en la historia rumana en la propia Rumanía con fines legitimadores de su nacionalismo, desde la Edad Moderna hasta el siglo XX, en comparación con el caso europeo y sobre todo español, donde el mito gético, nacido de la misma historia antigua de Rumanía, se ha transmitido y se ha constituido en objeto de apropiación consciente e inconsciente de la historiografía legitimadora de distintos poderes, a lo largo de las edades y en diferentes países y zonas geográficas. De este modo, se detectan con facilidad 
apropiaciones del pasado antiguo en Rumanía y en distintos países europeos, y no hace falta que nos vayamos lejos, pues tenemos muy buenos ejemplos en España tanto en el pasado como en el presente y, dentro de España, en casi todas las Comunidades Autónomas actuales, que por su propia juventud histórica y en pos de la controvertida historicidad de algunas, sienten la necesidad -una necesidad igualmente histórica, pues se ha dado en todas las épocas y en todos los ámbitos geográficos_ de buscar cualquier tipo de legitimación histórica y cultural como forma de justificar ya no sólo su propia existencia actual, sino también sus pretensiones nacionalistas y en algunos casos independentistas. Las apropiaciones del pasado no son sino lo que se ha dado en denominar el uso y el abuso de la historia, pero también de la Historia. Desde esa perspectiva, nuestro estudio constata el gran poder de legitimación y justificación del pretérito más remoto en diferentes momentos y circunstancias nacionales. Todo el pasado resulta válido para dicha finalidad, pero la Antigüedad mantiene una mayor idealización que permite generar genealogías prístinas y míticas de difícil refutación histórica hasta época muy reciente, como sucede con el mito gético del que hemos venido hablando y también con su expresión simbólica en la heráldica, ella misma una variante de la misma apropiación del pasado.

\section{NOTAS}

${ }^{1}$ PARKER, H. T., The Cult of Antiquity and the French revolutionaries, Chicago, 1937 (reimpr. Nueva York 1965); MOSSÉ, C., L'Antiquité dans la Révolution française, París, 1989. Sobre la mencionada campaña militar en relación con los descubrimientos que dieron lugar al nacimiento de la egiptología, ver por ejemplo DENON, V., Sin mañana: Viaje al Alto y Bajo Egipto durante las campañas del general Bonaparte, Gerona, 2005 (1 $1^{\text {a }}$ ed. París, 1802); RUSSELL, T.M., The Discovery of Egypt, Stroud, 2005.

${ }^{2}$ GUERCI, L., Libertà degli Antichi e libertà dei Moderni. Sparta, Atene e i "philosophes" nella Francia del'700, Nápoles, 1979; GUINZO, A., El legado clásico. En torno al pensamiento moderno y la Antigüedad clásica, Alcalá de Henares, 2002; SIGNES CODOÑER, J. (coord.), Antiquae lectiones: el legado clásico desde la antigüedad hasta la Revolución Francesa, Madrid, 2005.

${ }^{3}$ Federazioni e federalismo nell'Europa antica, Atti del Convegno (Bergamo, 21-25 settembre 1992) 'Alle radici della casa comune europea: storia e storiografia dell'Europa antica, 1', Milán, 1994; L'ecumenismo politico nella coscienza dell'Occidente, Atti del Convegno (Bergamo, 1821 settembre 1995) 'Alle radici della casa comune europea: storia e storiografia dell'Europa antica, 2', Roma, 1998; Identità e valori: fattori di aggregazione e fattori di crisi nell'esperienza politica antica, Atti del Convegno (Bergamo-Brescia, 16-18 dicembre 1998) 'Alle radici della casa comune europea: storia e storiografia dell'Europa antica, 3', Roma, 2001; Modelli eroici dall'antichità alla cultura europea, Atti del convegno (Bergamo, 20-22 novembre 2001) 'Alle radici della casa comune europea: storia e storiografia dell'Europa antica, 4', Roma, 2003; La cultura 
storica nei primi due secoli dell'impero romano, Atti del Convegno (Milano 3-5 giugno 2004) 'Alle radici della casa comune europea. Storia e storiografia dell'Europa antica, 5', Roma, 2006.

Destacan igualmente los trabajos de JENKINS, R. (ed.), El legado de Roma. Una nueva valoración, Barcelona, 1995; CANTARELLA, E., El peso de Roma en la cultura europea, Madrid, 1996; CAMBIANO, G., Polis. Un modello per la cultura europea, Roma/Bari 2000.

${ }^{4}$ LEAKE, J.A., The Geats of Beowulf. A study in the Geographical Mythology of the Middle Ages, Madison-Milwaukee-Londres, 1967; BUSUIOCEANU, A., Zamolxis, sau mitul dacic în istoria si legendele spaniole, Bucarest, 1985.

${ }^{5}$ GIL, L., Panorama social del humanismo español (1500-1800), Madrid, 1981 (2 ed. 1997); idem, Estudios del humanismo y tradición clásica, Madrid, 1984.

${ }^{6}$ BIZZOCCHI, R., Genealogie incredibili. Scritti di storia nell'Europa moderna, Bolonia, 1995; WULFF ALONSO, F., Las Esencias Patrias. Historiografía e Historia Antigua en la construcción de la identidad española (siglos XVI-XX), Barcelona, 2003.

${ }^{7}$ Podríamos mencionar algunos coloquios internacionales, como "Les Princes et l'bistoire, XIVe-XVIIIe siècles" (1994) -en colaboración con l'Institut historique Allemand (París)-, cuyas actas fueron publicadas en París-Versalles en 1996, o el más reciente "Les historiographes en Europe de la fin du Moyen Age à la Révolution française” (2003), cuyas actas fueron publicadas en Versalles en 2006. Estos estudios han prestado una especial atención a la importancia de la Historia en la educación de los príncipes, y también a la importancia de la mitología.

${ }^{8}$ En este sentido debemos destacar el I Congreso Internacional y V Coloquio del Grupo Europeo de Investigación Histórica "POTESTAS", con el título Europa: Historia, Imagen y Mito, celebrado en Castellón (2006), y cuyas actas fueron publicadas en 2008.

${ }^{9}$ Se puede citar como ejemplo la importancia de la traducción de la Germania de Tácito para la gestación del nacionalismo alemán. Y en cuanto al empleo de los análisis modernos en la conformación de las ideologías nacionalistas, debemos tener presente la importancia capital de la obra de Adam Müller y su traducción a las distintas lenguas europeas, como punto de referencia para su conexión con lo ario.

${ }^{10}$ Entre esos casos, citamos un ejemplo para el caso francés, por ser muy reciente el libro de DA SILVA, J. G., História Antiga e usos do Passado. Um estudo de apropiações da Antiguidade sob o regime de Vichy (1940-1944), en História e arqueologia em movimento, São Paulo, 2007.

${ }^{11}$ En la web de Instituto de Historiografía "Julio Caro Baroja" se recogen materiales y documentos, y los avances de los resultados del grupo de investigación, como se ha venido haciendo con los proyectos que han estado vigentes (http://www.uc3m.es/uc3m/inst/JCB/proyectos.html).

${ }^{12}$ Hes., Teog, 104-108.

${ }^{13}$ Sobre esta cuestión me remito a un artículo previo, CARBÓ GARCÍA, J.R., "Sobre la correcta denominación de los pueblos tracios del norte: dacios y getas", Flor.Ilib. 12, 2001, pp. 97-115. 
${ }^{14}$ Orosio, Hist., I, 16, 2: modo autem Getae illi qui et nunc Gothi ("pero los que hoy son godos eran en otros tiempos los getas").

${ }^{15}$ Jordanes, Get., IX, 60; X, 61-64; X-XI, 65-68. Sobre Jordanes y sobre la relación de su obra con la de Casiodoro, ver: COURCELLE, P., Histoire littéraire des grandes invasions germaniques, París, 1964, pp. 208-209; BRADLEY, D.R., "The composition of the Getica", Eranos 64, 1966, pp. 67-69; SVENNUNG, J., Jordanes und Scandia, Estocolmo, 1967, pp. 5-6 y 136141; WAGNER, N., Getica. Untersuchungen zum Leben des Jordanes und zur früben Geschichte der Goten, en Quellen und Forschungen zur Sprach-und Julturgeschichte der germanischen Völker, N.F. 22, Berlín, 1967, pp. 18-30; SVENNUNG, J., "Zur Cassiodor und Jordanes”, Eranos 67, 1969, 1-3, pp. 71-80; HACHMANN, R., Goten und Skandinavien, Berlín, 1970, pp. 15 y ss.; DAGRON, G., "Discours utopique et récit des origines. 1-Une lecture de Cassiodore-Jordanes: les Goths de Scandza à Ravenne", Annales. Économies. Sociétés. Civilisations, 26,2, 1971, pp. 290-305; REYDELLET, M., La royautè dans la littérature latina de Sidoine Apollinaire à Isidore de Sèville, Roma, 1981, pp. 255-267; TEILLET, S., Des goths à la nation gothique. Les origines de l'idée de nation en Occident du Ve au VIIe siècle, París, 1984, pp. 305-334; CROKE, B., "Cassiodorus and the Getica of Jordanes”, Classical Philology 82, 1987, pp. 117-134; GOFFART, W., The Narrators of Barbarian History, Princeton, 1988, pp. 43-44; HEATHER, P., "Cassiodorus and the rise of the Amals Genealogy and the Goths under Hun domination", JRS 79, 1989, pp. 103-128; HEATHER, P., Goths and Romans (332-489), Oxford, 1991, pp. 34-67.

${ }^{16}$ Isidoro, Etym., 9, 2, 89.

${ }^{17}$ Rodrigo Jiménez de Rada, Historia Gothica.

${ }^{18}$ Lucas de Tuy, Chronicon Mundi.

${ }^{19}$ Alfonso X el Sabio, Cron. Gen. : De los sabios de los Godos y de los sos conseieros.

${ }^{20}$ LEAKE, J. A., The Geats of Beownlf. A study in the Geographical Mythology of the Middle Ages, Madison, 1967, pp. 72-79.

${ }^{21}$ MARX, J. (ed.), Gesta Normannorum Ducum, 1914, I, pp. 2-3, citado por LEAKE, J.A., op.cit., p. 80: sistens reges habuit multos mirare philosophiae eruditione vehementer imbutos, Zeutan scilicet atque Dichineum, necnon Zalmoxen aliosque plures.

22 TEILLET, S, op. cit., p. 51, nota 63.

${ }^{23}$ Alonso de Cartagena, Anacephalaeosis.

${ }^{24}$ GONZÁLEZ FERNÁNDEZ, R., "El mito gótico en la historiografía del siglo XV", en Los visigodos. Historia y civilización. Antigüedad y Cristianismo, 3, Murcia, 1986, pp. 289-300.

${ }^{25}$ MENÉNDEZ PIDAL, F., ElEscudo de España, Real Academia Matritense de Heráldica y Genealogía, Madrid, 2004.

${ }^{26}$ Cosimo de Médicis, citado por BUSUIOCEANU, A., Zamolxis, sau mitul dacic in istoria si legendele spaniole, Bucarest, 1985, p. 186: “...vi sono per ornamento l'insegne de' Goti cioè saette e giogo all usanza degli Sciti, come Quinto Curzio riferisce, dicendose che $i$ Re di Castiglia volessero conservar segno di discendenza da medesimi Goti." 
${ }^{27}$ La fama de los arcos y flechas de los getas es constatada por las referencias en los autores antiguos. Lucano, por ejemplo, ensalza la fama del arco gético y sus versos serían después repetidos por Isidoro de Sevilla y por otros autores: "Armeniosque arcus Geticis intendite neruis" (Lucano, Pharsalia, VIII, 221). Séneca habla de las terribles flechas de los getas elevándose hacia el cielo: "...talis in coelum exilit arundo Getica visa dimitti manu” (Séneca, Hercules Oetaens, 818-819). Séneca parece basarse en un pasaje de Heródoto en el que, hablando de las divinidades de los getas, menciona que "cada vez que truena o relampaguea, disparan flechas al aire, indignados con el cielo, al tiempo que amenazan a la divinidad, pues no creen que exista ningún otro dios que no sea el suyo" (Heródoto, Historia, IV, 94). Y precisamente en la Península Ibérica, en la Baja Edad Media, el arzobispo toledano Rodrigo Jiménez de Rada relata en su obra que los godos "hacían arcos con cuerdas con gran maestría", para reproducir justo a continuación los versos latinos de Lucano que hacen referencia a esta información sobre los getas y que citábamos más arriba: "Y tensad los armenios arcos con las cuerdas de los getas" (Rodrigo Jiménez de Rada, Historia Gothorum, I, 10, 31).

${ }^{28}$ GONZÁLEZ FERNÁNDEZ, R., op. cit., p. 289 ss.

${ }^{29}$ WULFF ALONSO, F. y ÁLVAREZ MARTÍ-AGUILAR, M. (eds.), Antigüedad y franquismo (1936-1975). Serie Actas, Málaga, 2003. Sobre la concepción del símbolo del yugo y las flechas por los falangistas Juan Aparicio López y Rafael Sánchez Mazas, ver: APARICIO LÓPEZ, J., "El emblema de las J.O.N.S.”, El Fascio 1, Madrid, 1933, p.14; SÁNCHEZ MAZAS, R., "Haz y yugo", El Fascio 1, Madrid, 1933, p. 8 (fragmento de una conferencia dada en Santander y publicada por el Boletín de la Biblioteca Menéndez Pelayo, en 1927).

${ }^{30}$ CARBÓ GARCÍA, J.R., "Godos y getas en la historiografía de la Tardoantigüedad y del Medievo: un problema de identidad y de legitimación socio-política”, SHHA 22, 2004, pp. 179-206; ídem, "Sobre el origen del yugo y de las flechas en el blasón de los Reyes Católicos", en GARCÍA HOURCADE, J.J. (ed.), Memoria de Isabel la Católica, Murcia, 2005, pp. 245-260; idem, "Varia Hispano-Getica: Tracing the Possible Getic Origin of the Arrows Emblem on the Coat of Arms of the Catholic Monarchs and the Falange in Spain", en Eph.Nap 16-17, Cluj-Napoca, 2008, pp. 255-272; idem, "El mito gético en Europa: la invención de tradiciones y la búsqueda de legitimación historiográfica en la creación de un nuevo orden socio-cosmológico en el Período de las Migraciones", en Europa: Historia, Imagen y Mito, Castellón, 2008, pp. 95-111. Este último estudio es el resultado de una comunicación presentada en el I Congreso Internacional y V Coloquio del Grupo Europeo de Investigación Histórica "POTESTAS", al que ya nos hemos referido, y que tenía por título Europa: Historia, Imagen y Mito, en Castellón-Vinarós, entre el 23 y el 26 de octubre de 2006.

${ }^{31}$ La conferencia "La Dacia romana: un precedente cultural para la próxima integración de Rumanía en la Unión Europea”, en el Centro de estudios de la Universidad Wake Forest en Salamanca, el 1 de noviembre de 2006; la conferencia "De Dacia a Rumanía: pasado y presente de un recorrido histórico", en las Sesiones del Instituto Cultural Rumano de Madrid, pronunciada en la Embajada de Rumanía, Madrid, el 18 de febrero de 2009; la comunicación "Antigüedad, teatro e historiografía en la Rumanía del siglo XX", en el III Encuentro de Jóvenes Investigadores de Historiografía, "Historiografía y Artes Escénicas", Universidad Carlos III de Madrid, el 28 de octubre de 2009; y la ponencia invitada "Los orígenes de los 
rumanos en la historiografía del nacionalismo", en el Congreso Internacional: "Mitologías Políticas y Consciencias Nacionales", Universidad Carlos III de Madrid, del 5 al 7 de noviembre de 2009. Sendas versiones ampliadas de ambos estudios serán publicadas en los respectivos números monográficos de la Revista de Historiografía, del Instituto de Historiografía "Julio Caro Baroja", Universidad Carlos III de Madrid.

${ }^{3}$ MOXA, M., Cronograful Țării Românești, 1620; URECHE, G., Letopisețul Țării Moldovei, 16421647; COSTIN, M., Letopisețul Țării Moldovei, 1675; idem, De neamul moldovenilor, din ce țară au ieşit strămoşii lor, 1686 (publicada por vez primera por Mihai Kogălniceanu en 1852); NECULCE, I., Letopiseţul Țărâi Moldovei, 1743; CANTEMIR, D., Hronicul vechimii a romano-moldovalabilor, 1719-1722.

${ }^{3}$ POP, I.A., "Nations and Denominations in Transylvania (13th - 16th Century)", en LÉVAI, C. y VESE, V. (eds.), Tolerance and Intolerance in Historical Perspective, Cliob's Workshop II, vol. 9, Pisa, 2003, pp. 111-123.

${ }^{34}$ HITCHINS, K., "Religion and Romanian National Consciousness in Eighteenth-Century Transylvania", en Slavonic and East European Review, 57, 2, 1979, pp. 214-239.

${ }^{35}$ POMPILIU, T., "The Romanians from Transylvania between the Tradition of the Eastern Church, the Counter Reformation and the Catholic Reformation", en CRACIUN, M. y GHITTA, O. (eds.), Ethnicity and Religion in Central and Eastern Europe, Cluj, 1995, p. 181 ss.; POP, I. A., "Il patriarca Kiril Lukaris sull'unità etno-confesionale dei Romeni”, en GUIDA, F. (ed.), Etnia e confessione in Transilvania (secoli XVI-XX), Roma, 2000, pp. 19-28.

${ }^{36}$ METZELTIN, M., Las lenguas románicas estándar. Historia de su formación y de su uso, Oviedo 2004, p. 254.

${ }^{37}$ Uno de sus representantes más destacados fue Samuil Micu, con sus obras Istoria şi lucrurile și intîmplările românilor, Istoria Românilor y Brevis historica notitia originis et progressu nationis DacoRomanae, esta última publicada en Cluj en 1778. Escribió también Elementa linguae daco-romanae sive valachicae, Cluj, 1780, en colaboración con Gheorghe Şincai, que a su vez publicó, ya en 1811, Hronica românilor şi a mai multor neamuri. Entre las obras de Petru Maior, cabe mencionar Istoria pentru inceputul românilor în Dachia, y entre las de Ion Budai-Deleanu, De originibus populorum Transylvaniae.

${ }^{38}$ Como referencia general, ver TRENSÉNCYI, B., PETRESCU, D., PETRESCU, C., IORDACHI, C. y KÁNTOR, Z. (eds.), Nation-Building and Contested Identities. Romanian and Hungarian Case Studies, Budapest-Iaşi, 2001.

${ }^{39}$ CARBÓ GARCÍA, J.R., "Los orígenes de los rumanos en la historiografía del nacionalismo", Revista de Historiografía (en prensa).

${ }^{40}$ BLAGA, L, Zamolxe, Misterpăgân, Cluj, 1921. Ver el interesante análisis de DANA, D., "Le Zalmoxis de Lucian Blaga, entre construction et révolte: un aspecto du débat sur le "spécifique nacional» dans la Roumanie d'entre-deux guerres", en Caietele Echinox, 12, 2007, pp. 334-353.

${ }^{41}$ PÂRVAN, V., Getica. O protoistorie a Daciei, Bucarest, 1926. 
${ }^{42}$ CARBÓ GARCÍA, J.R., "Antigüedad, teatro e historiografía en la Rumanía del siglo XX", Revista de Historiografía (en prensa).

${ }^{43}$ CEAUŞESCU, I., Vom dakischen Staat zum sozialistischen Rumänien, Bucarest, 1985. Para la historiografía rumana de esta época, ver también DELETANT, D., "Rewriting the past: trends in contemporary Romanian historiography", en Ethnic and Racial Studies, 14,1, 1991, pp. 64-86; VERDERY, K., National identity under socialism: identity and cultural politics in Ceausescu's Romania, Berkeley, 1991.

${ }^{44}$ Sobre la tendencia "daco-romanista" en la historiografía rumana anterior a la revolución, ver ILLYÉS, E., History and ideology. The Daco-Roman theory in Romanian historiography, VienaStuttgart, 1982.

${ }^{45}$ DENSUŞIANU, N., La Dacie préhistorique, Bucarest, 1913.

${ }^{46}$ Ver, sobre todo, BRĂTESCU-VOINEŞTI, I.A., L'origine du peuple roumain et de la langue roumaine, Bucarest, 1942. 